\title{
Lexis
}

Journal in English Lexicology

Book reviews | 2019

\section{Herbert L. COLSTON, Using Figurative Language}

Cambridge University Press, 2015, 275 pages

\section{Günter Schmale}

\section{(2) OpenEdition}

\section{Journals}

\section{Electronic version}

URL: http://journals.openedition.org/lexis/3541

DOI: 10.4000/lexis.3541

ISSN: 1951-6215

\section{Publisher}

Université Jean Moulin - Lyon 3

\section{Electronic reference}

Günter Schmale, "Herbert L. colston, Using Figurative Language», Lexis [Online], Book reviews, Online since 23 August 2019, connection on 23 September 2020. URL : http://journals.openedition.org/lexis/ 3541 ; DOI : https://doi.org/10.4000/lexis.3541

This text was automatically generated on 23 September 2020.

\section{(c) (i) (9)}

Lexis is licensed under a Creative Commons Attribution-NonCommercial-NoDerivatives 4.0 International License. 


\title{
Herbert L. COLSTON, Using Figurative Language
}

Cambridge University Press, 2015, 275 pages

\author{
Günter Schmale
}

\section{REFERENCES}

Herbert L. Colston

Using Figurative Language. Cambridge University Press, New York, 2015. ISBN :

978-1-107-10565-2, Prix : $€ 79,275$ pages

1 Colston's study of figurative language use from a pragmatic perspective comprises six chapters of 40 to 50 pages each, apart from the introduction of 13 pages (thus a total of 230 pages) plus a very detailed contents, 7 pages of endnotes, 23 pages of references as well as a useful index of 3 pages.

Colston starts out from the following understanding of language production and use:

Using Figurative Language was born out of the idea that accounts of language production, use, comprehension, structure, underpinning, and change, for figurative and indirect but additionally all language, need to align with current understandings of not only human cognitive phenomena but also social, emotional, motivational, physical, and other human and animal functioning along with established explications of [...] all the layers of language and their nature. (p. xv)

3 The author thus addresses figurative language use as a complex social phenomenon which is being analyzed in an extensive and original way from different - pragmatic perspectives. Figurative language $(=\mathrm{FL})$, assimilated to indirect language, ${ }^{1}$ but not defined explicitly, seems to be understood as a "disconnection between surface form and intended meaning" (p. 231: endnote 1) for both figurative and indirect language forms owing to people's "not saying what the mean" (p. 1: title of the introduction). However, the author does not differentiate between figurative and indirect speech acts, given that the former have to be semantically non-compositional whereas the latter are 
not, and that figurative language is not necessarily indirect. ${ }^{2}$ His understanding of FL has thus to be derived from the different types of FL which are being discussed: rhetorical question, metaphor, idiom, metonymy, verbal irony, hyperbole, understatement, colloquial tautology and mixed figures (of three of the aforementioned types) (p.1f.). None of these types are being defined to be treated through examples taken from the author's personal collection, i.e. not a coherent corpus. ${ }^{3}$

4 Colston first deals with pragmatic effects, explained as "additional complex meaning [...] accomplished by a speaker's use of figurative language” (5), originating from the use of the different types:

[...] the term pragmatic effect is meant loosely as a reference to mental/internal activity taking place in a person, traceable to his or her encountering figurative as well as other language, usually when receiving (e.g., as an addressee, hearer, overhearer, reader, etc.) but also when he or she produces or even thinks about it. (p. 6)

5 However, in spite of the reference to addressees' interpretations this quotation might suggest, FL is in fact being analyzed in terms of "speaker intentions" (p. 3). The methodology put to work by Colston does not provide any empirical proof for the functions delineated.

The "corpus", or rather personal collection of isolated examples stemming from mainly non naturally occurring sources, consists of

instances of figurative and other language usage from popular, predominantly North American novels, movies, television programs, Internet videos, songs, advertisements, and other sources in both talk and text. (p. 8)

7 Admitting that "their noted possible differences from in-the-moment spoken figurative language and authentic written communications should be kept in mind" (8-9), i.e. of naturally occurring language productions attested in a systematically assembled large corpus, Colston nevertheless claims that the "vividness etc." (p. 9) of his corpus "can offset concerns about genuineness" (p. 9). A claim which can unfortunately not be shared from a scientific corpus linguistic perspective, especially as one has to rely on the author's interpretation of isolated instances of FL, e.g., "It's late in the evening, she's wondering what clothes to wear." (p.160) from Eric Clapton's song Wonderful Tonight of intuitively non-figurative utterances and as Colston himself stresses the importance of context elsewhere (p. 66, p. 193).

8 The study's main value therefore resides in an original, extremely well-documented reflection on pragmatic effects and issues of common ground as one of the reviewers states on the book's back cover:

It contains numerous original insights that empiricists will be able to mine for their studies for years to come. (Roger Kreuz, University of Memphis)

Colston's study of FL addresses two main issues: pragmatic effects (PE) and the use of FL. Referring to Roberts and Kreuz's [1994] empirical investigation, Colston starts out by detailing PEs of simile, metaphor, hyperbole, rhetorical question, irony, understatement and indirect request. Their metadiscourse goals are being described as enrichment or emphases of meaning, expressing negativity and effective guidance of action in other people (p. 19), the latter two playing an important role in avoiding face threat. After discussing different approaches to pragmatics - Speech Act Theory, Gricean and Relevance Theory (p. 22ff), Colston briefly discusses psychological and 
then, more extensively, sociocultural effects which may affect FL usage and comprehension such as social knowledge about speakers/hearers, shared knowledge about interlocutors, familiarity in interlocutors, enablement of social information (social structure, language, culture), egocentrism in speakers, social information interacting with language processing (p. 48-52):

[...] when people are in unfamiliar social situations, their ability to derive subtle pragmatic effects from a use of a figurative utterance can suffer. (p. 52)

Colston then delineates PEs, first general ones, followed by those specific to single figures or figure families. General PEs are ingratiation, "a roundabout compliment delivered to addressees" (p. 67), mastery, demonstration of the speaker's expertise in handling difficult situations, persuasion, social engineering, designed to accommodate the social status of participants, catalyzation, "the degree of social interaction among interlocutors" (p. 70) and efficiency, "concentrated meaning with relatively little quantity of language" (p.70). Specific PEs are expressing negativity, enhancing meaning, highlighting discrepancies, objectification, i.e. "mentioning or reference to preexisting cultural values [...] ensconced in fixed phrases" (p. 75), identification (with cultures or social groups), humour, emotion expression/elicitation, extollation, politeness (e.g., through euphemisms) or impoliteness, tension reduction and Machiavellianism. ${ }^{4}$

11 PEs can originate from different types of triggers. These are linguistic, structural, juxtaposition - "metaphor may have emerged as the dominant form of figurative language because of this careful balance of affordances and constraints" (p.90) -, metapragmatic, social, psychological, idiosyncratic, stylistic/register or embodied causes (cf. p. 85-99).

The second main part of Colston's study deals with aspects of FL use, differentiating how it is used (p. 100-143) and what use is (p. 144-190). First discussing "the necessity of common-ground considerations for successful language use and comprehension" (p.103), Colston then analyzes the role of common ground, grosso modo shared linguistic, semantic, cultural knowledge, in the use of the different types of FL listed above. As far as metaphor is concerned Colston states:

Class-inclusion accounts argue that metaphors are comprehensible because interlocutors share knowledge about categorical structures and memberships. (p. 106)

13 However, memory, availability, automaticity and style (p. 119-124) also have an impact on use and understanding of FL. Colston nevertheless admits that certain aspects of common-ground usage such as appropriateness, aptness and indirectness (p. 127-131) pertain to any form of language production and comprehension, not just FL. One might even ask oneself if the same conclusion does not apply, for instance to impoliteness, tension reduction or extollation (see above). In short, one can be impolite, reduce tension or praise without resorting to figurative language.

Colston finally points out the importance of "multimodal means of delivery and figurative language usage" (p. 140), e.g. of gaze in face-to-face communication or of " blends of text [...] and images" in written texts. ${ }^{5}$

Having developed forms of FL use, Colston then turns to what FL use consists of, dealing with various phenomena germane to the recourse to figurative expressions. After having proposed a table of categories of language use - e.g., live versus recorded, or language A versus language B, fiction versus nonfiction, etc. (p. 147) - Colston mentions 
the necessity of corpus-assisted discourse studies (CADS), given that "an awful lot of language would need vigilant assessment" (p. 149) because of the prevalence of FL, but his conception of CADS does not seem to reflect the current state of research. Even if certain linguistic indicators (cf. p. 154) might facilitate automated research of instances of $\mathrm{FL}$, that is from a corpus-based perspective elucidating the usage of specific lexical items ${ }^{6}$ machine-supported research is impossible as far as the multimodal integrated nature of discourse is concerned. To this, Colston adds some interesting remarks on FL creativity and hackneyedness (p.160-172), both being governed by a variety of different contextual factors.

The book finally deals with "Figurative Use beyond Language" (p. 178-180), stating that "Irony and its pragmatic effects can be readily conveyed through essentially any medium of human meaning communication." (p.178), e.g., "ironic body posture" (p. 178), conveyed by any multimodal means in general. Time (p. 180-184) or audience size (p. 184) may, on the other hand, limit pragmatic effects.

Colston concludes by advocating a "broadened view of language comprehension" (p. 228) which

may require a new approach to notions such as "meaning" and "pragmatics". If more psychological phenomena as described here are playing a role in what occurs inside and between speakers as the comprehend language and are tightly interwoven in that comprehension, then perhaps meaning should encompass more than just cognitive/propositional content. Other tangible conscious experiences such as emotions, attitudes, moods, alignments in the sense of devotions or loyalties, and others may belong as well. [...], language is so intertwined into all we do in our cognitive, social and emotional lives that we must attend to the full minds, bodies, cultures, and groups doing this meaning making to properly account for it. (p. 228-229)

In order to carry out an analysis of such a "broadened view of language comprehension ", Colston stresses that "empirical support" for a variety of different aspects pertaining to the understanding of $\mathrm{FL}$ is essential:

The bottom line may be that no one best way exists to metatheoretically approach figurative cognition. Each of these approaches garners some empirical support. What might thus emerge as optimal is some hybrid mix of each approach containing linguistic, cognitive, social, embodied, and evolutionary ingredients. (p. 226)

19 An honorable credo towards the study of figurative language which will, however, necessitate considerable interdisciplinary work based on a large corpus, ideally comprising conversational material from naturally occurring speech exchange systems in order to be able to found interpretations on addressees' reactions rather than on analysts' intuitions. 


\section{BIBLIOGRAPHY}

ROBERTS R. M. \& KREUZ R. J., 1994, “Why do people use figurative language?”, Psychological Science $5 / 3,159-163$.

\section{NOTES}

1. Unless Colston sees them as synonyms which does not transpire throughout his book.

2. Thinking of metaphors such as "the early bird catches the worm" which can easily be understood in context provided "normal" world knowledge on account of a transparent relationship of source and target domain.

3. Cf. "Most of the examples used in this book..." (p. 227) which underlines the fact that Colston does not quote utterances, sequences, occurrences from a coherent corpus providing significant proof.

4. See the table p. 141 summing up pragmatic effects for speakers.

5. Cf. also Multimodal Indicators (p. 153) in chapter 5.

6. Thus not from a "corpus-driven", bottom-up, perspective, which may at best allow the collection of recurrent concordances.

\section{AUTHORS}

\section{GÜNTER SCHMALE}

Günter Schmale, Université Lyon 3 Jean Moulin, France. 